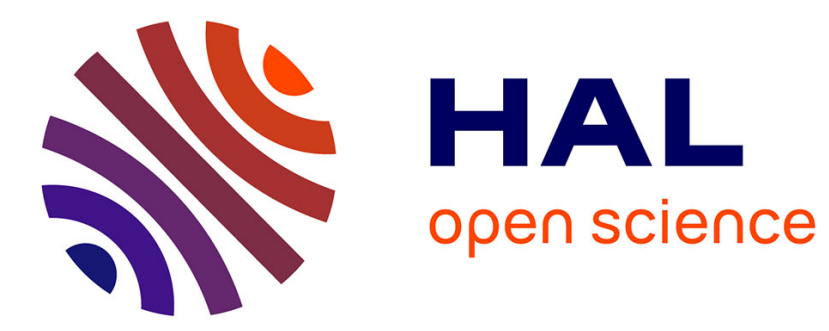

\title{
High Efficiency Interleaved Power Electronics Converter for wide operating power range
}

Kevin Guépratte, Pierre-Olivier Jeannin, David Frey, H. Stephan

\section{To cite this version:}

Kevin Guépratte, Pierre-Olivier Jeannin, David Frey, H. Stephan. High Efficiency Interleaved Power Electronics Converter for wide operating power range. APEC 2009, 2009, Washingon, United States. hal-00364103

\section{HAL Id: hal-00364103 https://hal.science/hal-00364103}

Submitted on 25 Feb 2009

HAL is a multi-disciplinary open access archive for the deposit and dissemination of scientific research documents, whether they are published or not. The documents may come from teaching and research institutions in France or abroad, or from public or private research centers.
L'archive ouverte pluridisciplinaire HAL, est destinée au dépôt et à la diffusion de documents scientifiques de niveau recherche, publiés ou non, émanant des établissements d'enseignement et de recherche français ou étrangers, des laboratoires publics ou privés. 


\title{
High Efficiency Interleaved Power Electronics Converter for wide operating power range
}

\author{
K.Guépratte, P-O.Jeannin, D.Frey, H. Stephan \\ Kevin.guepratte@g2elab.inpg.fr, pierre.olivier.jeannin@g2elab.inpg.fr \\ Grenoble Electrical Engineering (G2Elab), Thales Systemes Aeroportes
}

\begin{abstract}
The paper focuses on a new driving strategy for improving the efficiency of power converters even if they are not used at there nominal power. The converters are using an output filtering structure with magnetical coupling. These filtering structures are usually employed to minimize in a significant way the mass of the converters. These filters are normally sized to work with a fixed number of phases. To optimize the magnetic components, it is necessary to take into account some physical constraint, as the iron sections of the magnetic circuits and saturation problems. These problems are tricky, especially in case of the variation of the number of phase. A new control strategy is presented for interleaved and multilevel structure. Finally converter simulation results are compared with the experimental results. A $1.6 \mathrm{~kW}(115 \mathrm{~V})$ converter realization is presented.
\end{abstract}

\section{Index Terms-Power converters, Interleaved, Power efficiency}

\section{CONTEXTE, INTRODUCTION}

One of the challenges for power electronic devices is to participate at the global reduction of energy consumption and therefore to increase the converter's efficiency. One of the most interesting benefits of the interleaved structures is to provide a high efficiency in wide power range (from few percent of converter's nominal power to its nominal power).

Many applications, like solar power plant or VSD systems with variable torque loads, need very wide power range [1]. A classic converter that has a nominal efficiency above $95 \%$, will see his efficiency decreasing to $85 \%$ if it works at $50 \%$ of his nominal power. If the output power continues to decrease to $25 \%$ of the nominal output power, the efficiency will be reduced at about $50 \%$.

In this paper, we present an original control strategy to ensure a high efficiency, independently of the output power. It is based on an interleaved power electronics structure. Part II presents the power electronics structures and the control strategy. In order to optimize the volume, it will show the specific constraints on the magnetic device used in these structures. In the part III, we will explain how the magnetic devices have been adapted for this original control strategy. To validate the results, two demonstrators has been built: a 4 cells multi-level and a 6 cells single phase 115V-17A inverter. Part IV presents the experimental setup and the results.

\section{POWER ELECTRONICS STRUCTURES AND CONTROL STRATEGY}

This part presents different structures that could be used, i.e. interleaved or Multi-Level structures [2] [3]. In this paper, we will use both structures together in order to obtain the best performances in terms of efficiency and volume.

\section{A. Interleaved structure.}

This structure is composed of different paralleled cells. The driving signal of each cell is phase shifted. This structure allows to reduce by a factor $\mathrm{N}$ ( $\mathrm{N}$ is the number of cells) the output current ripple and increases the apparent switching frequency by the same factor $\left(\mathrm{N}^{*} \mathrm{~F}_{\text {switching }}\right)$ [4]. For a defined output ripple frequency, the interleaved structure needs a smaller switching frequency than traditional power converters. Another advantage is that the output power is distributed between the different cells. This allows reducing the current rating of the different transistors. The switching and conduction losses are therefore smaller than for classical structures.

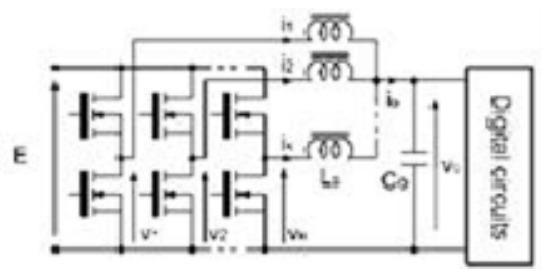

Figure 1: Interleaved structure [9]

\section{B. Control strategy}

This method offers an interesting solution to increase the converter efficiency for output power much lower than the nominal value. The idea is to use only a part of the cells, so that each cell always works close to its nominal power as shown on figure 2 and 3 . This solution is particularly interesting for converters dedicated to battery or solar cells applications. Each cell was dimensioned for a nominal power of $200 \mathrm{~W}$.

Our control strategy has the characteristic to maintain the output switching frequency constant, even if the number of cells changes. This induces that the switching frequency of each cell changes, depending on the number of cells used. The table 1 shows the switching frequency of each cell versus the number of cells used.

\begin{tabular}{|l|l|l|l|l|l|l|}
\hline N of active cells & 1 & 2 & 3 & 4 & 5 & 6 \\
\hline $\begin{array}{l}\text { Switching frequency of } \\
\text { each cell (kHz) }\end{array}$ & 292 & 146 & 97 & 73 & 58 & 48 \\
\hline
\end{tabular}

Table 1 : Switching frequency of each cell versus the number of cells used

The increase of the interleaved cell number with the output power induces a reduction of the switching frequency of each switch. Therefore the switching losses are reduced and the global efficiency will be higher. 


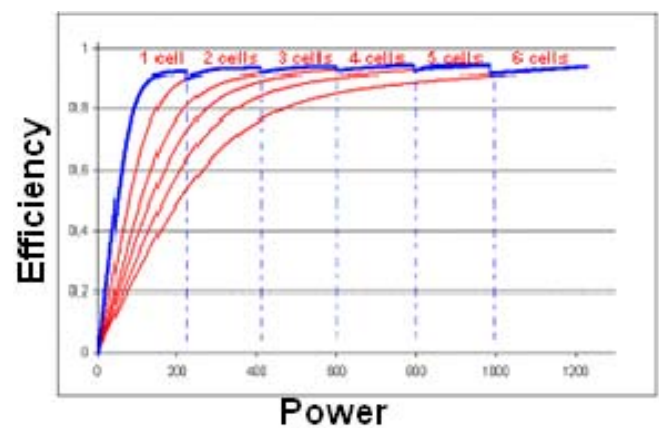

Figure 2: Efficiency optimization (blue), efficiency on variable cells (red).

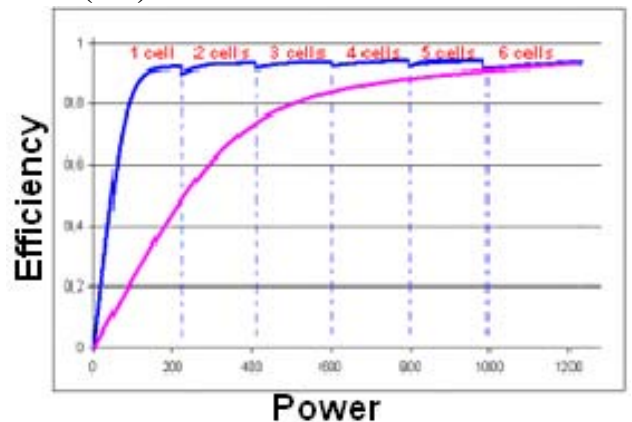

Figure 3: Efficiency optimization (blue), efficiency on classic inverter (red).

In this control strategy, all cells will not work simultaneously. To ensure the same lifetime and limit the constraint on the power transistors, the working time of each cell should be equal. In fact, if only one cell would be used, the losses in the cell's power components will be much higher. This is due to the necessary increase of the switching frequency to maintain the output frequency constant. In this case, it would be necessary to use bigger transistors but this will produce an increase of the losses, or to upsize the cooling system of each transistor.

A solution is to equalize the operating time of each output phase by making a circular bearing system of the cells.

\section{Magnetic filtered output voltage}

In interleaved converters with filtered output voltage, the filters represent an important part of the converters weight. To solve this problem, it is necessary to find the best compromise between the weight of the input and output filters and the weight of power electronic elements. The classical solution uses independent inductors as shown on Figure 4. This method imposes a very important weight and the magnetic device conception is therefore crucial. Multi-level and/or interleaved structures allow interesting opportunities.

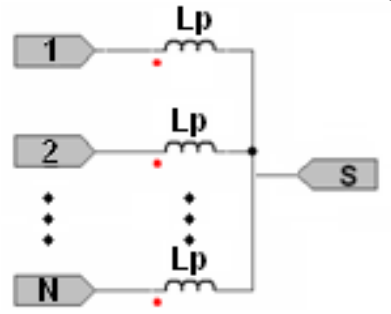

Figure 4: Filtered output voltage with independent inductors [8]
To realize improved magnetic devices there are several possibilities. Two of the classical structures are presented below.

- Monolithic coupler [5] [6], which uses only one magnetic core Figure 5.

- Coupling transformers between the different output phases of the interleaved converter. On Figure 6, the Cyclic cascade structure is presented [7]. Note that other coupling strategy using transformer can be used, like showed in Figure 16.

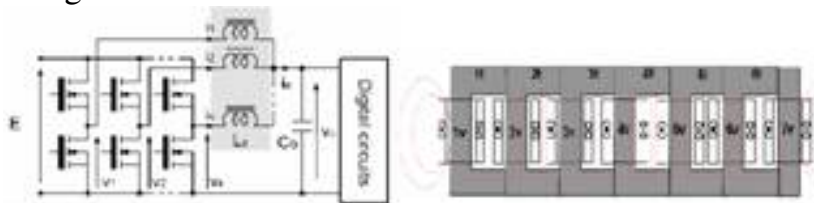

Figure 5: Interleaved structure with monolithic coupler [9]

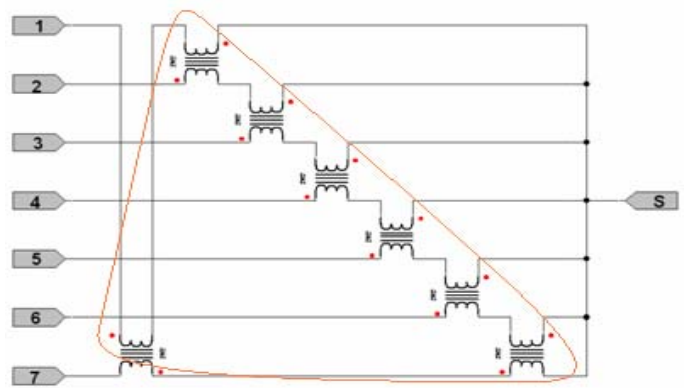

Figure 6: Interleaved structure with coupling transformers

For the efficiency optimisation, we will see how to use an interleaved converter using a magnetic coupler at the output with only a reduced number of phases.

The main problem is due to in the coupling between the phases. In the case of the interleaved structure with coupling transformers, it is necessary to ensure that the current can always pass through the different magnetic circuit. This should be done even if some converter cells are shut down. A solution consists in short-circuiting the phases of the magnetic coupler as presented on Figure 7.

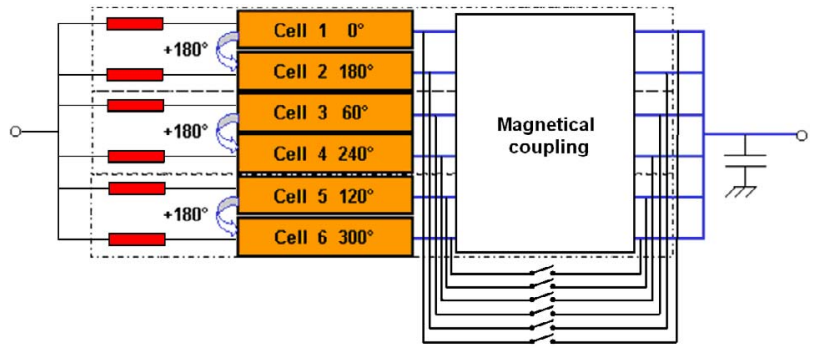

Figure 7: Additionnal switching to short-cut the unused phases of the magnetic output filter.

The necessity to adapt the switching frequency of the converter is not only for guarantee the rate of the output current ripple but also to avoid the saturation of the magnetic circuits for both technologies (monolithic or coupling transformer). 


\section{EFFICIENCY CONTROL AND MAGNETIC STRUCTURE}

The choice of the output filtering structure must be made according two requirements: the magnetic losses and the capability of functioning with a variable number of cells. To minimize the magnetic structure and to reduce the losses, it is important to choose an output filtering structure that permit to keep a symmetrical distribution of magnetic flow in all the parts of the magnetic circuits.

\section{A. Interphase transformers}

The studies of the "magnetic couplings" are based on transformer whose each winding is connected like shown on Figure 6. The solution presented is based on individual transformers with two windings, which are produced with standard cores. This configuration makes it possible to transfer energy between each phase.

To operate, the connection of the transformers should be a closed loop. When a cell is not in use, the current can not circulate in the phase anymore. So the loop between all the transformers is open. This implies that the AC part of the current will be the same from one phase to another, but the DC part will be different [10], due the transformer (Figure 8). These current unbalances will have a significant effect on the magnetic field in the magnetic circuits.

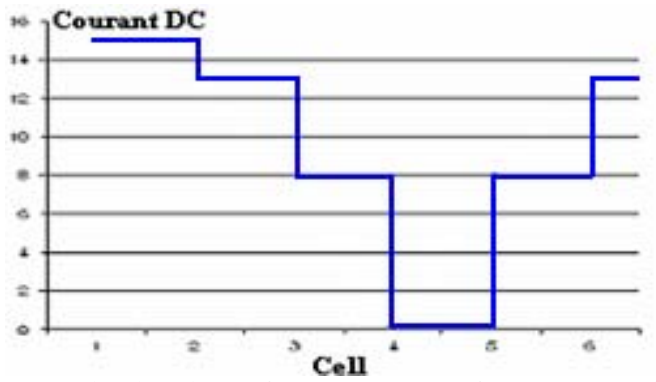

Figure 8: Distribution of the DC part of the current in each winding, for a converter with 6 cells. In this structure the cell 4 is unused.

To achieve the continuity of operation, a solution is to short-circuit the unused windings connected to the cell like shown Figure 9. By short-circuiting the filter, it is possible to close the loop between the different transformers. On Figure 9 (a), we can see that the circulating currents in phases 3 and 5 are connected by the transformer connected on phase 4 . The DC courant will be also equitably distributed into all the magnetic structure Figure 9 (b),

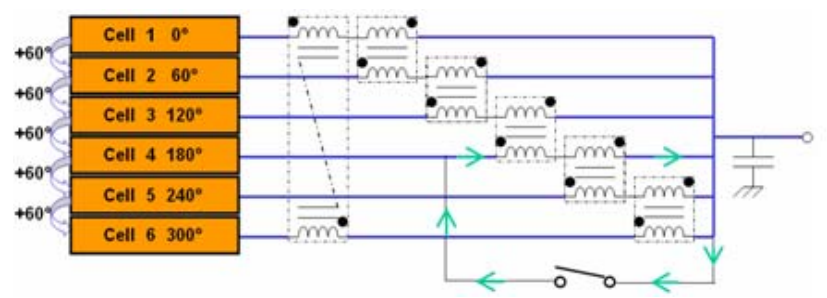

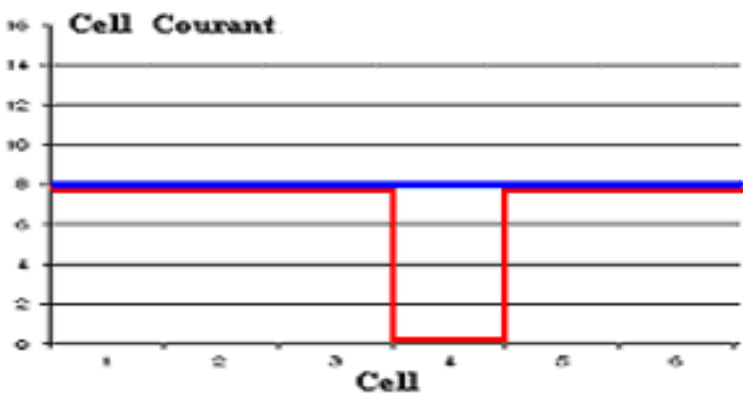

b)

Figure 9: (a) Example of 6 cell structure with short-circuit component on cell 4. (b) In blue, courant into the different winding. In blue, courant from the converter.

In practice, the coupling between phases 3 and 5 will generate additional losses. However, in case of reduced power this solution ensures a good compromise. The principal disadvantage of this system is the number of additional semiconductors required. The components must be controlled at turn on and turn off, be bidirectional in current and voltage. Several configurations of semiconductor devices can then be adopted (see Figure 10).
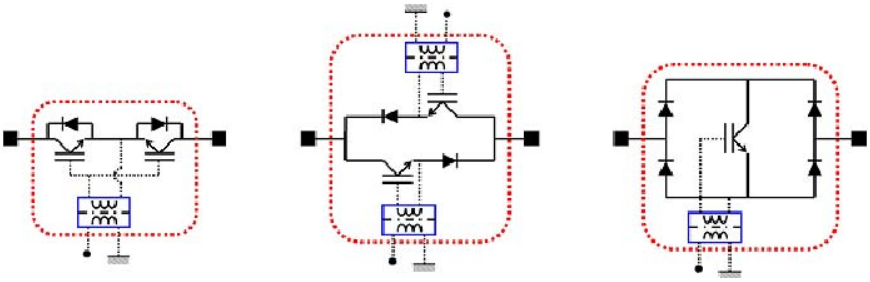

Figure 10: Switch semiconductors configuration with Transistors base.

Figure 11 presents time domain waveforms of the inverter with magnetic couplings. It shows the current ripple of the six-cell converter.

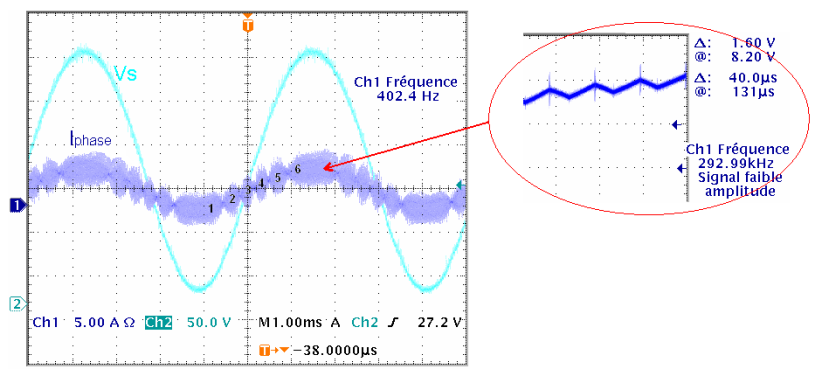

Figure 11: Experimental inverter waveforms with 6 cells

On Figure 12, the converter works with 5 cells. One of the six cells is short-circuited and the FPGA (control circuit) has changed the phase shift. With one cell less, the courant ripple increase of a sixth. To keep it at the same level of a converter using 6 interleaved cells, we can increase the switching frequency of cells like it is showed on table 1. 


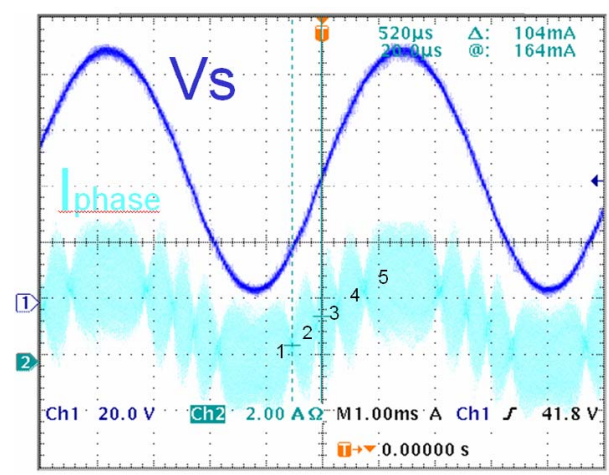

Figure 12: Experimental inverter waveforms with 5 cells

The Figure 13 presents time domain waveforms for the 6 interleaved cells inverter with only 5 cells working and no short-circuit. When the current increase, the ripple becomes very high, this is due to the decrease of the value of the apparent inductance (due to the magnetic core saturation).

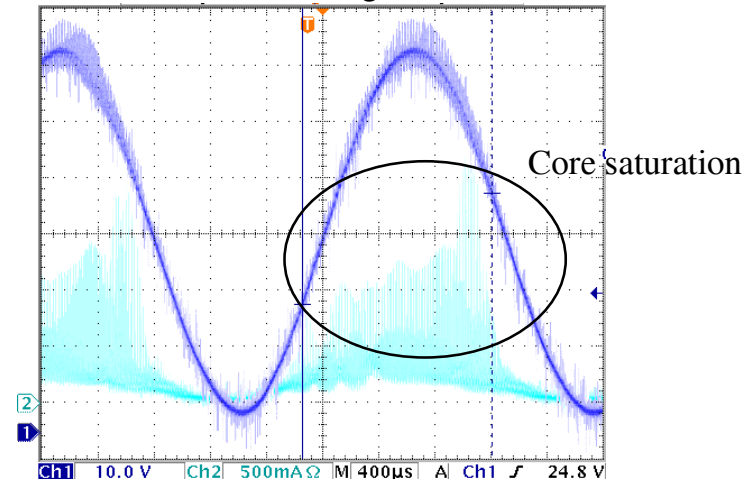

Figure 13: Experimental inverter waveforms with 5 cells and no short-circuit.

In the case of interphase transformer, one of the drawbacks of this filtering method is that the magnetic core section depends on the number of phases and of the switching frequency. As the magnetic elements can not be changed during use, this strategy imposes to modify the switching frequency of each cell according to the equation (1).

$$
S_{\text {fer }}=\frac{\frac{E}{4}}{4 \times N_{\text {spire }} \times B e_{\max } \times f_{\max } \times N_{\text {phase }}}(1)
$$

Table 1 gives the switching frequencies associated with a 6 cells converter. The magnetic core is dimensioned in the most critical case where the maximum magnetic induction is calculated with one cell. This condition is adapted for the case of a converter which optimizes the output with a variable number of cells.

Another effect is due to the reduction of the maximum induction (before magnetic saturation) in a material versus the frequency of use (Figure 14). This phenomenon increase the switching frequency of the converter (table 2 compare to the table 1) in case of reduces number of cells in use.

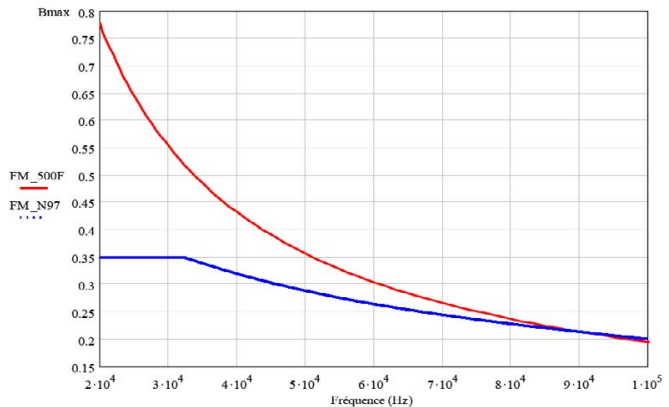

Figure 14: Maximum induction according to the frequency of two usual magnetic materials $(500 \mathrm{~F}, \mathrm{~N} 97)$ for a density of losses of $300 \mathrm{~mW} / \mathrm{cm} 3$

For our application, it is preferable to have the variation of the magnetic induction versus frequency as low as possible, so the N97 core seems to be appropriate. The core $500 \mathrm{~F}$ with a very significant variation, it is well adapted to an application with a fixed number of cells.

\begin{tabular}{|l|l|l|l|l|l|l|}
\hline N of active cells & $\mathbf{6}$ & $\mathbf{5}$ & $\mathbf{4}$ & $\mathbf{3}$ & $\mathbf{2}$ & $\mathbf{1}$ \\
\hline $\begin{array}{l}\text { Switching } \\
\text { frequency of each } \\
\text { cell (kHz), 500F }\end{array}$ & $\mathbf{2 0}$ & $\mathbf{9 0}$ & $\mathbf{1 5 0}$ & $\mathbf{2 4 0}$ & $\mathbf{3 3 0}$ & $\mathbf{6 6 0}$ \\
\hline $\begin{array}{l}\text { Switching } \\
\text { frequency of each } \\
\text { cell (kHz), N97 }\end{array}$ & $\mathbf{3 0}$ & $\mathbf{4 0}$ & $\mathbf{6 2}$ & $\mathbf{1 1 0}$ & $\mathbf{2 1 0}$ & $\mathbf{4 2 0}$ \\
\hline
\end{tabular}

Table 2: Active switch frequency of the converter according to the number of cells. For magnetic core 500F and N97.

Another possible magnetic structure is presented on Figure 15. It allows using a variable number of cells, Figure 16. However, the cells are always working by pair. A coupling transformer is use for a pair of cells; each cell is phase shifted of $180^{\circ}$ from the other cell of the pair, Figure 15 . The drawback of this magnetic structure is that coupling between all phases does no longer exist.

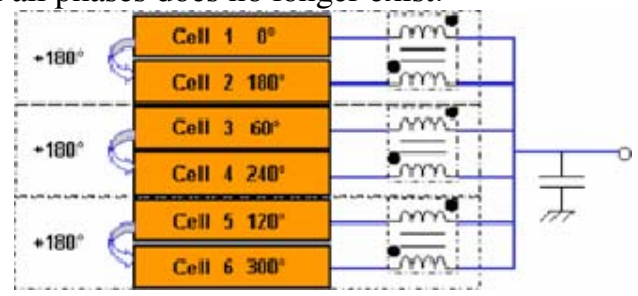

Figure 15: Pair cells working method

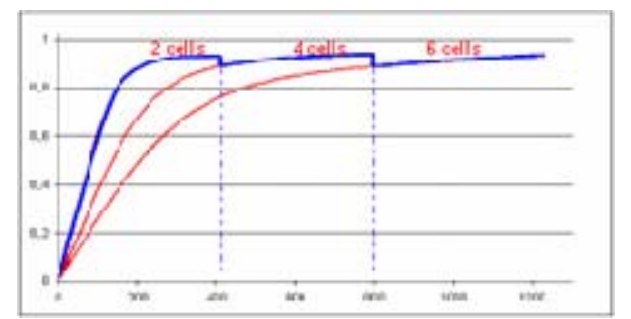

Figure 16: Efficiency optimization (blue), efficiency on variable cells (red).

The number of transformer is divided by two compared to figure 6 , but the cross section of magnetic circuit 
of each transformer is twice bigger, and the global volume is bigger. However, the volume is smaller comparing of the use of fully independent inductances as presented in figure 4. Therefore, this method is a compromise between volume, efficiency optimisation and simplicity of implementation.

\section{B. Monolithic transformers}

In monolithic structures, the different windings are on the same magnetic core. They have high filtering performances for a very low weight whereas are more difficult to realise. Figure 17 and Figure 18 illustrate this symmetry. The monolithic couplers can be produced many different ways. The most current topology is called in "scale". In this topology a problem of over sizing appear, because in some columns of the magnetic circuit there are strong concentrations of magnetic flow, Figure 17, [9] and [13].

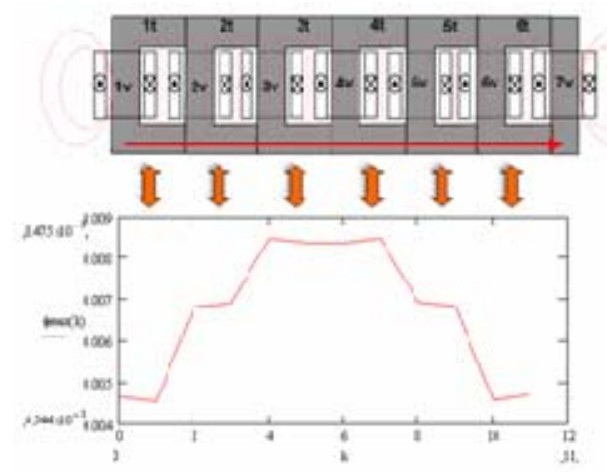

Figure 17: Distribution of the maximum induction value in a monolithic magnetic structure using a topology in "scale".

Another structure is the structure named "circular". It allows having a uniform distribution of flow in the whole magnetic structure, Figure 18. This circular topology is based on standard magnetic cores which are associated together. It can be used only for an even number of cells, equal or higher than 4 [14].

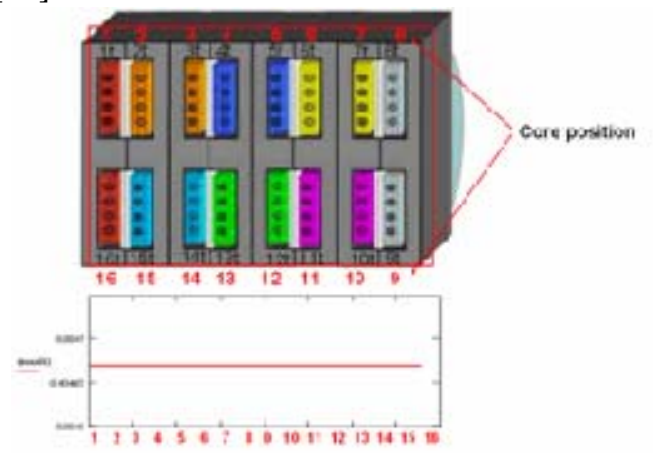

Figure 18: Core diagram and magnetic field in a circular topology.

One drawback of this structure is in the case of electrical (and magnetic) unbalances. Indeed if a winding is open, the current in this winding will be null. So the magnetic reluctance will be very low (in this leg), and the magnetic flow will pass mainly by this leg. It will change the global flow distribution in the entire magnetic circuit, and it will cause some local magnetic saturation. To avoid this drawback, the classical solution is to oversize the magnetic circuit section (and of course the weight of the magnetic part of the converter). The end of this part will show how this structure can be used for operation with a variable number of phases despite this drawback.

For the following study, we chose to work on the circular monolithic coupler, due to its simplicity and the good distribution of the magnetic flow. The most of the following results are obtained on a test bench with 4 and 6 phases circular magnetic structure.

A drawback is that the magnetic circuit doesn't contain an air-gap, the flows generated by each phase are totally channelled by the unused leg and each phase can then be interpreted like a simple independent inductance [7]. The ripple of the resulting current in each phase will be at the switching frequency and an unequal concentration of flow occurs in the magnetic circuit. It is necessary to oversize the coupler according to the tolerated number of unused legs.

Figure 19 presents time domain waveforms for the inverter with coupling transformers. The converter work with 4 stages.

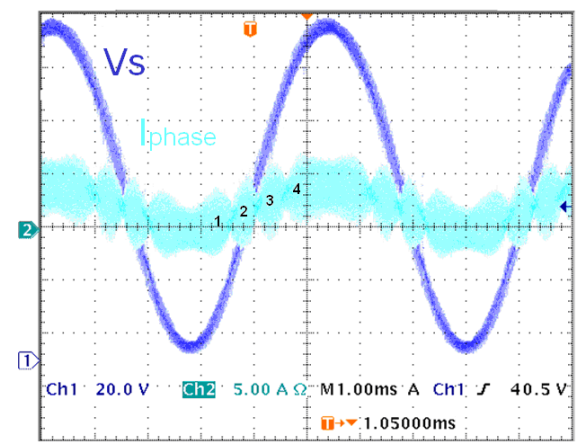

Figure 19: Experimental inverter waveforms with monolithic filter and 4 cells

If we use only two phases (on the four of the total converter), the magnetic filter is equivalent of two independent inductors with no air-gap. So the magnetic core will saturate, Figure 20 and Figure 21 a.

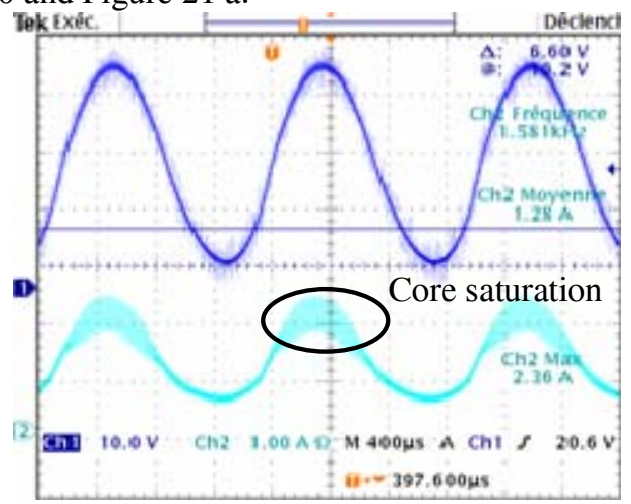

Figure 20: Experimental inverter waveforms with 2 cells and no short-circuit.

If we connect in short-circuit the unused phases, a courant appear on the unused winding, Figure 22. The flows will take another way and will not use the arms in short-circuit, Figure $21 \mathrm{~b}$. 


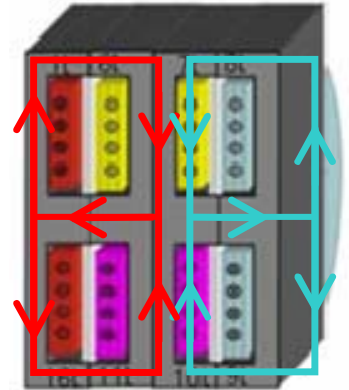

a)

Figure 21: Circulation of flow in a coupler with 4 cells. In (a) 2 cells are used and no short-circuit. In (b) 2 cells are used and short-circuit on the both un-used phases.

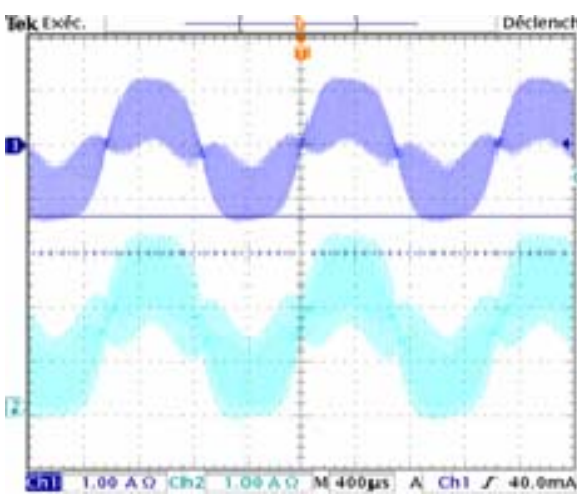

Short-circuit widing courant

\section{Phase courant}

Figure 22: Experimental inverter waveforms with 2 cells and short-circuit.
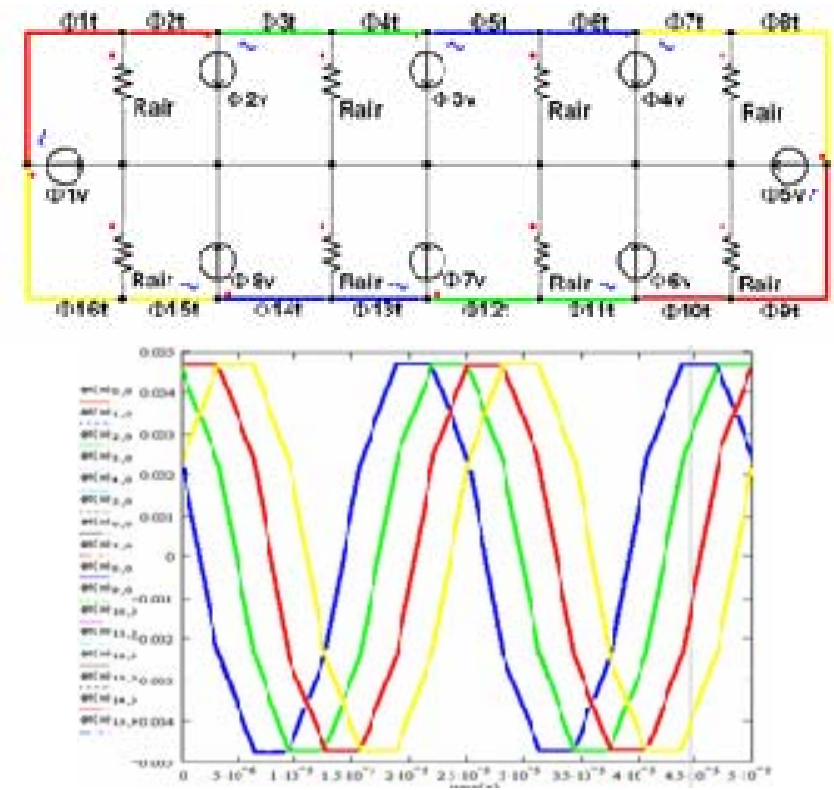

Figure 23: Diagram of reluctance in case of a circular topology. The different colours show the zones where the flows are identical. The curves represent flows in these various zones.

In the transverse bars of the coupler, flows have all identical forms. Figure 23 shows the magnetic flow repartition in the magnetic circuit. Identical flows are located by colors.
We can noticed, that there is a symmetrical repartition of flow in the magnetic circuit.

In the case of some cells are unused, to balance the magnetic flow into the core, a solution is to short-circuit the winding of the unused cells. Note that two symmetrical cells must be short-circuiting at the same time (Figure 24)Figure 18.

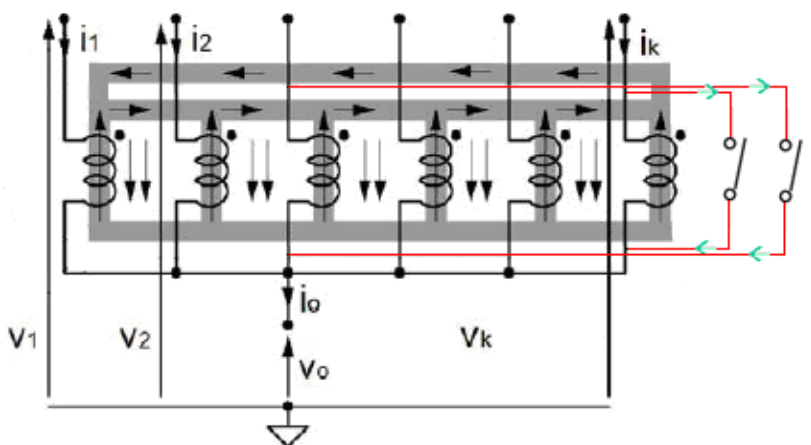

Figure 24: Control of the flow distribution by short cutting symmetrical phases.

In the case of the monolithic coupler, the iron section does not depend of the number of phases. The equation (2) always guaranteed a constant iron section even if the number of operating cells varies. So for magnetic flow saturation considerations, there is no need of increasing the switching frequency (note that it was not the case with using interphase transformer presented in part III-A). However it can be interesting to modify the switching frequency to keep constant the output current ripple.

$$
S_{\text {fer }}=\frac{E}{8 \times N_{\text {spire }} \times B e_{\max } \times f_{\text {max }}} \text { (2) [16] }
$$

\section{EXPERIMENTS AND VALIDATION}

Two tests benches have been developed; the first one is composed of 4 interleaved cells based on independent inductances and monolithic magnetic filters. Each cell is composed of a 3 level multi-level NPC converter. The Second one is composed of 6 interleaved simple-level cells based on magnetic filters transformers. The whole system is driven by an FPGA. Figure 25 and Figure 26 shows these tests benches.

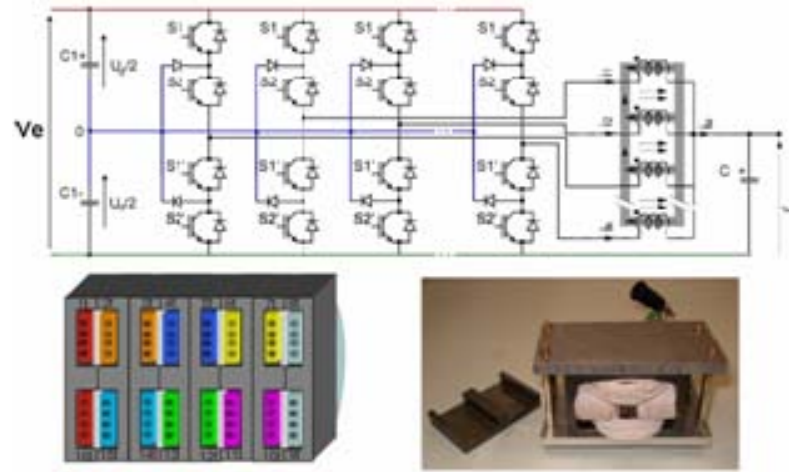

Figure 25: 4 interleaved cells based on 3 level multi-level NPC converter and monolithic magnetic filters. 
Each cell is able to provide a power of $400 \mathrm{~W}$. The global converter power is $1.6 \mathrm{~kW}$. The power electronic structure developed allows an auto-adaptive control. This control depends of the number of cells and the current and voltage measurements in the structure. The FPGA calculates the different control signals for each cell. The numerical structure into the FPGA is composed of a microprocessor NIOS II of Altera ${ }^{\circledR}$.

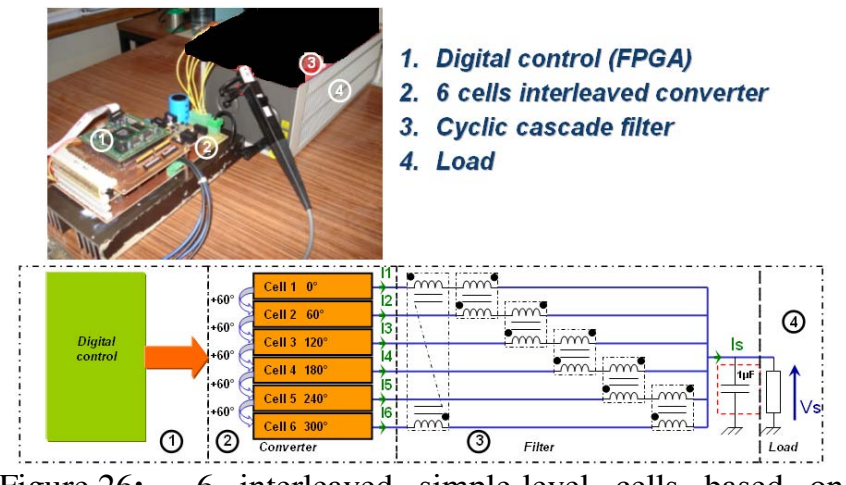

Figure 26: 6 interleaved simple-level cells based on interphase transformers.

The processor analyzes the data coming from measurements (tension and current), it adapts PWMs in real time for functioning with variable number of phases versus the measured powers. His function is also to control the output voltage of the converter. The PWM module is a high DPWM resolution according to the model developed in [15]. A USB connection is also use with software of diagnostic and system requirements.

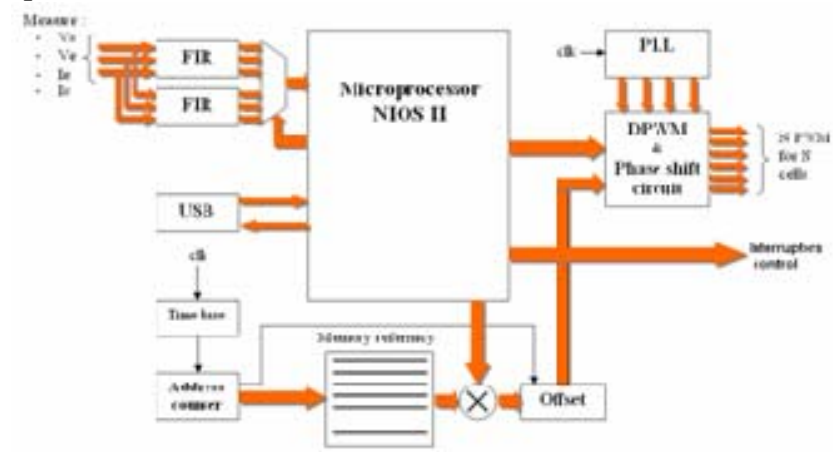

Figure 27: Numerical structure of the FPGA

\section{CONCLUSION}

This paper shows an original control strategy that improves the energy efficiency of power converters. If we use a power electronics converter at $50 \%$ of its nominal power, the part of the losses from the input energy is divided by 3 by using this control strategy.

Part 2 and 3 presented how classical magnetic coupling Method (interphase transformer cyclic cascade and monolithic coupler) can be used. It presents also a simple method using coupling transformer that is compatible with this control strategy (Figure 15).

Part 4 validate this approach by showing experimental setup.
Another advantage of using this control strategy is to permit the fail mode operation of the power electronics converter. In the 4 cells interleaved power converter presented in part 4 , if one cell fails, the power electronics converter can continue operating with the other cells.

\section{REFERENCES}

[1] J-A. ROOKS, A-K. WALLACE, "Energy Efficiency of VSDs" IEEE Industry Applications Magazine May/June 2004

[2] T. A. Meynard, H. Foch, P. Thomas, J. Courault, R. Jakob, M. Nahrstaedt, "Multicell Converters: Basic Concepts and Industry Applications", IEEE Transactions on Industrial Electronics 2002, vol.49, no.5, pp955-964

[3] S. Dieckerhoff, S. Bernet, D. Krug, "Power Loss-Oriented Evaluation of High Voltage IGBTs and Multilevel Converters in Transformerless Traction Applications", IEEE transaction on power electronics, vol 20, no 6 novembre 2005

[4] M.Stadler, J.Pforr, "Multi-phase Converter for Wide Range of Input Voltages with Integrated filter Inductor", Power Electronics and Motion Control Conference, 2006. EPE-PEMC 2006. 12th International

[5] Pit-Leong Wong,Q. Wu, Peng Xu, Bo Yang, F. C. Lee, "Investigating Coupling Inductors in Interleaving QSW VRM", IEEE Applied Power Electronics Conference, APEC, 2000, pp. 973-978

[6] Pit-Leong Wong,Q. Wu, Peng Xu, P. Yang, F. C. Lee, "Performance Improvements of Interleaving VRMs with coupling inductors", IEEE Transactions on Power Electronics, 2001,pp.499-507

[7] P. Zumel, O. Garcia, J. A. Cobos, J. Uceda, "Magnetic Integration for Interleaved Converters", IEEE Applied Power Electronics Conference and Exposition, APEC, 2003, pp.1143-1149

[8] In Gyu Park, Seon Ik Kim , "Modelling and analysis of multi-interphase transformers for connecting power converters in parallel", IEEE 1997, pp1164-1170

[9] F. Forest, T.A. Meynard, E. Labouré, V. Costan, E. Sarraute, A. Cunière, T. Martiré, "Optimization of the supply voltage system in interleaved converters using intercell transformers", IEEE Transactions on Power Electronics, vol. 22, no.2, pp 934-942, 2007

[10] P. Zumel, O. Garcia, J. A. Cobos, J. Uceda, "Magnetic Integration for Interleaved Converters", IEEE Applied Power Electronics Conference and Exposition, APEC, 2003, pp.1143-1149

[11] Valentin Costan, Thierry Meynard, François Forest, Eric Labouré, "Core losses measurements in intercell transformers for interleaved converters", EPE 2007

[12] B.A. Welchko, T.A. Lipo, T.M. Jahns, S.E. Schulz, "Fault tolerant three- phase AC motor drive topologies; a comparison of features, costs, and limitations", IEEE Trans. on Power Electronics, vol. 19, pp. 11081116, July 2004.

[13] T. A. Meynard, F. Forest, E. Labouré, V. Costan, A. Cunière, E. Sarraute, "Monolithic Magnetic Couplers for Interleaved Converters with a High Number of Cells", CIPS, 2006

[14] V. Costan, T.A. Meynard, "Topologies Circulaires de Transformateurs Inter-cellules pour des Convertisseurs Parallèles Entrelacés", 2007, EF, Toulouse

[15] Santa C. Huerta, A. de Castro, 0. Garcia, J.A. Cobos, "FPGA based Digital Pulse Width Modulator with Time Resolution under 2 ns", IEEE 2008, pp4244-1668.

[16] V. Costan, "Etudes des pertes fer dans les transformateurs inter-cellules", thèse de doctorat en génie électrique, Laboratoire Plasma et Conversion d'Énergie, 2008. 